\title{
Literatura y sociedad. Algunos ejemplos de la presencia de Jaime I en la Región de Murcia, a través de diversos contextos escritos. Siglos XIX y XX
}

\section{Literature and Society. Some examples of the presence of Jaime I in the Region of Murcia, through various written contexts. Nineteenth and twentieth centuries}

RAMÓN DOMÉNECH VILLA phonascus67@gmail.com

UNED

\begin{abstract}
Resumen: Cada lugar se caracteriza por tener su héroe particular. Sería muy difícil encontrar dos héroes compartidos en diferentes espacios físicos, mucho más si estos se encuentran limitando entre sí. En la actualidad podría ser comparable a las rivalidades existentes en ciertas competiciones deportivas, incluso podríamos plantearnos la existencia de ciertos paralelismos entre estos y aquellas situaciones bélicas producidas en siglos anteriores. La Región de Murcia, Andalucía y el País Valencià, compitieron en un particular duelo de protagonismo monárquico, con claros parentescos familiares, durante el siglo XIII. Ante el predominio de uno u otro monarca, y sin contar con su protagonismo destacado podríamos hacernos multitud de preguntas: ¿Desaparecieron todas las referencias al rey Jaime I, dentro del marco de la sociedad murciana, una vez pasados los siglos con otro rey como protagonista? ¿Sería posible encontrar referencias a él, en contextos relacionados sociales de la Región de Murcia? ¿Jugó la literatura de la época algún papel en este sentido? ¿El ciudadano de la Región podía crear un contexto no formal de aprendizaje histórico?
\end{abstract}

Palabras clave: Región de Murcia; literatura; Jaime I; sociedad; aprendizaje.

\begin{abstract}
Each site is characterized by its particular hero. It would be very difficult to find two different heroes in shared physical spaces, even if they are border regions. In this days and age, this fact could be comparable to existing rivalries in certain sport competitions; besides, we may even look on the existence of certain parallelisms between these latter ones and those warfare situations produced in earlier centuries. The Region of Murcia, Andalusia and the Valencian Country competed each other in a particular feud for a monarchic prominence with clear family relationships during the XIII century. Given the predominance of one or another monarch, and regardless of their leading role we might ask ourselves many questions: Did all references to King James I disappeared, in the context of society Murcia, once that centuries passed by with another king as protagonist ? Would it be possible to find references to him in social contexts related to Murcia? Did the literature of the time play any role in this regard? Would Murcia citizens have created a non formal-context of historical learning?
\end{abstract}

Keywords: Region of Murcia; Literature; James I; Society; Learning.

DATA PRESENTACIÓ: 03/10/2014 ACCEPTACIÓ: 07/12/2014 • PUBLICACIÓ: 15/12/2014

SCRIPTA, Revista internacional de literatura i cultura medieval i moderna, núm. 4 / desembre 2014 / pp. 125 - 146 ISSN: $2340-4841 \cdot$ doi:10.7203/SCRIPTA.4.4360 
Ramón Doménech Villa. Literatura y sociedad. Algunos ejemplos de la presencia de Jaime I en la Región de Murcia, a través de diversos contextos escritos.

\section{Introducción}

Cuando el 2 de febrero de 1266 el Rey Jaime I de Aragón, acudiendo en ayuda de su yerno Alfonso $\mathrm{X}$ el Sabio, entraba bajo el arco, llamado de las Siete Puertas, en la ciudad de Murcia, orientadas estas al mediodía ${ }^{1}$, poco podía sospechar que su nombre, figura, imagen y referencia, aparecería siglos posteriores en los contextos más variados imaginables, como alusión a actitudes, en expresiones con diferentes sentido, en variadas creaciones artísticas o en publicaciones literarias en cualquier género imaginable.

Dos ejemplos ilustrativos de esta situación, los suficientemente distanciados en el tiempo, nos sirven como introducción a este artículo cuyo objetivo es corroborar la presencia de la figura del rey, durante parte de los siglos XIX y XX y dentro de la actual Región de Murcia, así como en sus límites más cercanos, en las más variadas situaciones y en otras referencias que tienen como autores a personajes oriundos o relacionados con las diferentes comarcas de esta tierra, junto aquellos que quisieron conjugar historia, tradición, anécdotas, literatura y marco geográfico enlazados con un mismo hilo conductor, algunas veces de forma consciente y otras parece que menos

La primera de las referencias nos lleva al mes de junio de 1889, en concreto al día 14, cuando en el Teatro Príncipe Alfonso de Madrid², se estrenaba D. Jaime el Conquistador clasificada como «juguete cómico-lírico-bailable, en un acto, dividido en dos cuadros» con letra en verso D. Federico Jaques Aguado y música de D. Manuel Fernández Caballero (Murcia 1835-Madrid 1906).

Una obra que, dentro de las diferentes curiosidades, no debió ser del gusto del escritor mexicano Amado Nervo (Jalisco 1870-Montevideo 1919), pues según él mismo indica en la crónica teatral que escribió el 15 de mayo de 1896 para el diario El Nacional: «D. Jaime el Conquistador es una zarzuelita en la cual hay todo, menos argumento, pero abunda en situaciones cómicas; su música, como del Maestro Caballero, es muy agradable y ha sido aplaudida por el respetable» ${ }^{3}$.

$1 \mathrm{Al}$ mismo tiempo que la ciudad y huerta eran repobladas por cristianos de origen catalán y aragonés.

2 Situado en el Paseo de Recoletos y demolido en el año 1989.

3 Con un tema recurrente, la figura idealizada de D. Jaime, el doble sentido de la palabra «conquistador» y la sociedad de final del siglo XIX, parece que no se llevaban tan mal del todo. Tanto es así que, por citar un ejemplo más, en otra obra con ciertos paralelismos con la anterior: Granés y Cotó (1898: 8) En el prólogo de la obra, mientras que se presentan los personajes, se señala lo siguiente:

Personajes de la obra: (...)

la señora del inglés,

que es una vieja feroz;

un viejo verde, otro nuevo

Don Jaime, el conquistador;

y un clarinete ambulante

que soplando echa el pulmón

y siempre pide limosna

en tono de mi bemol.

SCRIPTA, Revista internacional de literatura i cultura medieval i moderna, núm. 4 / desembre 2014 / pp. 125 - 146 ISSN: 2340-4841 · doi:10.7203/SCRIPTA.4.4360 
Ramón Doménech Villa. Literatura y sociedad. Algunos ejemplos de la presencia de Jaime I en la Región de Murcia, a través de diversos contextos escritos.

Para el segundo de los modelos es necesario avanzar hasta la fecha del 17 de junio de 1937, porque ese día, y a las tres y veinticinco de la tarde, la ciudad de Cartagena, ya alterada habitualmente al encontrarse inmersa en plena Guerra Civil, se convulsionó y tembló, aún más si era posible, debido a una explosión ocurrida en el muelle de «La Curra». Un incidente en el interior del acorazado Jaime $I$, en el momento en el que se producían los trabajos de mantenimiento y reparación de la nave, acabó con la vida de más de 300 de sus tripulantes y el hundimiento de uno de los símbolos marítimos de fidelidad al gobierno democráticamente establecido. Aquel barco, con una tripulación de más de 800 marineros daba con su estructura de hierro en el fondo del Mar Mediterráneo, un triste presagio de lo que acontecería solo unos meses más tarde.

Estas dos descriptivas alusiones, bastante cargadas de simbolismo, nos sirven como muestra para conocer qué podremos encontrar si continuamos con la lectura de estas líneas: referencias, artículos, investigaciones, relatos, crónicas o noticias que tendrán como fuente original el mundo de la prensa, junto a otras publicaciones de carácter local, regional y nacional, una muestra de la producción literaria de cada época (no obligatoriamente realizada por imprentas y editoras de la Región), adoptando formatos sorprendentes, junto a justificaciones inimaginables en aquel febrero de 1226.

Religión, historia, humor, música y patriotismos particularmente subjetivos, se mezclarán con tradiciones, leyendas y tragedias relativas a un personaje que, aparentemente olvidado y postergado, pese a su significación en el marco geográfico tratado, adquiere un protagonismo, inconsciente algunas veces, y donde se ha intentado respetar, dentro de lo posible, un orden cronológico en sus apariciones, junto a otros criterios de agrupación y exposición contextualizada.

\section{A modo de anécdota}

Pasear por las calles de cualquier municipio o localidad de la Región de Murcia puede presentar diferentes curiosidades, una de ellas es la relativa a la denominación de los centros educativos, siempre tan simbólicos y descriptivos de una identidad, simbolismo, vivencia o recuerdo. Resulta curioso comprobar cómo el rey de Aragón, Jaime I, no posee ni un solo centro educativo que le recuerde en toda la geografía murciana. Sin embargo su yerno posee, al menos, seis centros con su nombre, incluido un Instituto de Enseñanza Secundaria en la capital. Aunque puede ser para muchos algo anecdótico, para otros puede dar lugar a preguntas sobre el tratamiento, reconocimiento y relación del rey Jaime con la sociedad murciana, sobre todo tomando como referencia la historia y su devenir y, por encima de otras cosas, el conocimiento acerca de su papel y la relevancia del mismo para el espacio dentro del marco geográfico al que nos referimos.

Si deambulamos por las arterias de la capital de la Región existe un hecho que llama la atención de manera significativa; yerno y suegro comparten espacio geográfico respecto al callejero local, formando una curiosa «T» invertida, con la parte superior que triplica la inferior, siendo la primera 
Ramón Doménech Villa. Literatura y sociedad. Algunos ejemplos de la presencia de Jaime I en la Región de Murcia, a través de diversos contextos escritos.

un «paseo» ${ }^{4}$ y la segunda una sencilla calle de dirección única. Para aquellos que desconocen la ciudad dejamos abierto el acertijo para que intenten averiguar cuál corresponde a cada uno de ellos.

\section{Celebraciones, cabalgatas, desfiles, discursos y exposiciones.}

A diferencia de lo que sucede en la actualidad, los diarios locales de hace dos siglos se convertían en portavoces de las noticias y hechos más relevantes que sucedían, no solo en los pueblos limítrofes sino también en provincias y localidades que se encontraban fuera de la demarcación geográfica «de influencia». Muchos de ellos se nutrían de las colaboraciones de sus lectores, publicando aquellos contenidos de relevancia e interés, algunos de los cuales hasta eran repetidos en diferentes ediciones.

Cualquier acto podía tener un interés destacado. Así se puede observar en el diario Las Provincias de Levante (diario de la noche editado en Murcia), cuando el 18 de julio de 1891 publicaba la siguiente referencia relativa a la feria de la ciudad de Valencia de ese año. Con motivo de la inauguración de un monumento al rey hayamos un primer acercamiento, que nos sirve de aproximación a otras ramificaciones del artículo, cuando leemos: «La inauguración del monumento al rey D. Jaime I, será sin duda solemnísima, siendo representada en ella todas las provincias del antiguo reino de Valencia y Mallorca».

Dos semanas más tarde se daba razón de la correspondiente cabalgata «histórico-floral ${ }^{5}$ » (Las Provincias de Levante 1-08-1898) celebrada durante los festejos realizados, no sin alguna duda del periodista, al no estar presente en dicho acto, pues el comienzo de su artículo así lo parece indicar: «He aquí el orden de la que ayer debió verificarse en la hermosa ciudad de Turia». Según la crónica; el rey de Aragón participó en la tercera parte con todo un real acompañamiento que ilustraba la historia de la ciudad y del reino: «Raimundo Guillén de Entenza, Pedro Ferrer, Ximen de Tarazona (...), caballo del rey conducido por dos palafreneros $(\ldots) »$.

En términos de similar contexto periodístico, aunque diferente localización y fuente, colabora con su artículo D. Emilio Ruiz Mira cuando, días antes del número publicado el 18 de agosto de 1899, escribe al director del Heraldo de Murcia, para relatarle las fiestas de la cercana ciudad alicantina de Elche: «con que este culto y hospitalario pueblo honra anualmente a su querida patrona en el misterio de su Ascensión augusta». Con tal motivo, según relata el columnista y colaborador accidental: «Por la noche hubo una gran retreta en la cual tres bandas (...) acompañaban a una magnífica cabalgata que representaba la entrada del rey D. Jaime el Conquistador en esta morisca ciudad».

La prensa diaria también encontraba un espacio para dar cuenta de discursos pronunciados fuera

4 Que curiosamente entre los habitantes de la ciudad se conoce con el nombre de «Tontódromo».

5 Respecto a las referencias ortográficas se ha preferido actualizar todas aquellas que presentaban algún tipo de duda en su interpretación y lectura, incluso las que podrían ser erratas de imprenta propias de los textos.

SCRIPTA, Revista internacional de literatura i cultura medieval i moderna, núm. 4 / desembre 2014 / pp. 125 - 146 ISSN: 2340-4841 · doi:10.7203/SCRIPTA.4.4360 
Ramón Doménech Villa. Literatura y sociedad. Algunos ejemplos de la presencia de Jaime I en la Región de Murcia, a través de diversos contextos escritos.

de la Región, y la Península, por ciudadanos ligados fuertemente a ella. Tal es el caso de la siguiente referencia a Jaime I que aparece en El Eco de Cartagena con fecha de 16 de agosto de 1912, a raíz del discurso pronunciado en Ceuta, por el Mantenedor de los Juegos Florales de la ciudad en tales fechas, Tomás Maestre Pérez (1857-1936), alicantino de Monóvar pero pronto afincado en Murcia y catedrático de Medicina Legal en la Universidad de Madrid. En la segunda página del ejemplar de ese día, en un texto que era continuación de días anteriores, y que continuaría en los siguientes, bajo la sección «Los moros en España»; se podía leer:

\begin{abstract}
Los moros y nosotros convivimos sobre el mismo terreno durante la Edad Media. Las armas hablaron casi todos los días entre islamistas y cristianos. Pero siempre hemos respetado la religión, la familia, la propiedad los usos y costumbres y hasta las propias leyes de los musulmanes. Díganlo, si no, los fueros de Toledo, de Salamanca, de Ávila, de Zamora, de Alcalá, de Cuenca, de Baeza, de Zaragoza, de Teruel; díganlo los de Tudela, de Cáceres, de Badajoz, de Sevilla, de Murcia, de Córdoba; los de pueblos de nuestro Levante dados por el Rey Don Jaime el Conquistador, las primitivas Cartas pueblas y privilegios otorgados por Monarcas asturianos y leoneses...
\end{abstract}

En esta misma línea oratoria y discursiva, que se observaba en páginas de diversos diarios de la Región, se encuentra esta adaptación, ahora desde un perfil político puro, aparecida bajo la misma cabecera, tres días más tarde de la publicación de la anterior referencia, bajo el título «Conversación sobre el catalanismo», a propósito de una intervención del político referenciado dentro del artículo:

\begin{abstract}
Pedro el Grande y Jaime I (...) todo fue recordado con elogio por el señor Ossorio y Gallardo ${ }^{6}$, para lamentar como uno de nuestros mayores extravíos «El de no considerar esas glorias como nuestras, en no llamarnos a la parte de esas glorias genuinamente españolas, con lo cual, prescindiendo nosotros de la participación que nos está adjudicada en tales empresas, hemos otorgado a los demás un monopolio del que luego nos lamentaremos». (El Eco de Cartagena, 19-08-1912)
\end{abstract}

El mismo diario, originalmente editado en la ciudad departamental recogería, dieciséis años más tarde; el 6 de agosto de 1928, la participación española en la Exposición Internacional de Barcelona, dedicando un pabellón a las Bellas Artes, donde Aragón y Cataluña estarían representadas, entre otros por: «D. Jaime I el Conquistador, con las gestas y manifestaciones más señaladas de su siglo».

La prensa regional y la figura de Jaime I seguirían formando un todo común para señalar aquellas grandes exposiciones y encuentros internacionales realizados en nuestro país. En este caso como parte del conjunto de obras de arte que representarían al Reino de Murcia en la Exposición IberoAmericana de Sevilla. La mención que podemos leer aparece en el ejemplar del 4 de mayo de 1929, en diario Levante Agrario ${ }^{7}$, publicado en la ciudad de Murcia.

6 Exgobernador de Barcelona. Diputado aragonés.

7 Órgano de la Federación Agraria e Instructiva de Levante.

SCRIPTA, Revista internacional de literatura i cultura medieval i moderna, núm. 4 / desembre 2014 / pp. 125 - 146 ISSN: 2340-4841 $\cdot$ doi:10.7203/SCRIPTA.4.4360 
Ramón Doménech Villa. Literatura y sociedad. Algunos ejemplos de la presencia de Jaime I en la Región de Murcia, a través de diversos contextos escritos.

De esta manera, en el artículo «El Reino de $\mathrm{Murcia}^{8}$ y la exposición de Sevilla», se señala que: «la provincia de Murcia estará representada por una serie de obras de arte antiguo, entre las que cita la del pintor murciano Cristóbal de Acebedo (1580?-1644)», se trata de la Aparición de la Virgen de las Mercedes al Rey D. Jaime I, obra que se encuentra en el retablo mayor de la iglesia del convento de la Merced de la capital.

En parecidos términos se redacta la referencia que encontramos en el Boletín Bianual de la Junta del Patronato del Museo Provincial de Bellas Artes de Murcia (1928-29) Bajo el epígrafe; «El Reino de Murcia (Murcia-Albacete). En la exposición Ibero-Americana de Sevilla» (pp. 58-64).

El verano de ese mismo año 1929, también sirvió para que las páginas de El Levante Agrario y de El Eco de Cartagena, recogieran las celebraciones con motivo del centenario de la conquista de Mallorca por parte del rey, que se celebrarían durante el mes de septiembre, que a continuación recogemos en el mismo orden que aparecían:

En los presentes momentos la Unión de Municipios españoles, se ocupan de la preparación de la Asamblea Municipalista que ha de celebrarse en Palma de Mallorca a fines de verano o comienzos de otoño, coincidiendo con las fiestas con que dicha Capital conmemora el centenario de la Conquista de las Baleares por Jaime I de Aragón. (Levante Agrario. 22-06-1929)

El alcalde ha recibido una carta del conde de Maceda participándole que el rey irá en Septiembre ${ }^{9}$ para asistir a las fiestas del séptimo centenario de la reconquista de las Islas por don Jaime el Conquistador. (El Eco de Cartagena. 06-08-1929)

\section{Almanaques, anuarios o boletines; aprendizaje no formal contextualizado.}

La figura del rey Jaime también estaba presente en las publicaciones con formato de anuarios, calendarios o similares. Es curioso comprobar la variedad de artículos y trabajos que estos podían presentar, convirtiéndose en auténticos manuales de aprendizaje histórico y tradicional, además de relaciones entre provincias limítrofes.

Durante el primer decenio del siglo XX, el 31 de julio de 1909, se podía leer en el interior del Boletín de las Cámaras oficiales de Comercio, Industria y Navegación y Agrícola de Murcia ${ }^{10}$, un amplio artículo titulado Valencia, que contenía unas prometedoras, y nada tópicas, primeras líneas:

\footnotetext{
8 Reino formado en ese momento por las provincias de Albacete y Murcia.

9 En este caso, y en otros parecidos, se ha optado por conservar la grafía original de mayúscula en los días de la semana, meses...

10 Una revista mensual «dedicada al estudio y fomento del Comercio, la Industria y la Agricultura, especialmente en la provincia de Murcia».
} 
Ramón Doménech Villa. Literatura y sociedad. Algunos ejemplos de la presencia de Jaime I en la Región de Murcia, a través de diversos contextos escritos.

Valencia no sólo es «la patria de las flores», como todos los poetas la llaman desde el latino Claudiano (...): uno de los centros mayores de cultura de España, y aun puede decirse que de el mundo, y el baluarte finísimo de la libertad. [...] Tomada Valencia por los moros en el año 714, estuvo bajo el dominio de los sarracenos hasta 1238, en que las armas de D. Jaime el Conquistador la redimieron del yugo musulmán (p. 501)

Para continuar con un poema de Mosén Jaime Ferrer (ib. p. 502) del año 1276, algo que sería muy llamativo en la actualidad, por el uso del catalán, y, casi impensable en las páginas de los diarios actuales de la Región de Murcia. Con estos antecedentes merece la pena traerlo hasta aquí:

Mes lo Rey en Jaume vostron pare amat

Eli ha muda l'Escut posant per Divisa

Barres d'Aragó en Pavés quadrat

Com usen les dones, puis esta Ciutat

Te el nom femení, é aixi de esta guisa

Sobre el Camp de roig é Corona de or

Les ha concedides lo Ratpenat

Que cria en sa Tenda sos fills sens paor

Mentres durá el Sití, como sabeu señor

Prudent gerolifich ab que eus ha mostrat

La manya é valor ab que ha treballat

E així guanyá el nom de Conquistador.

Y finalizar el artículo señalando, con una curiosa y particular reflexión:

Pero lo que el Rey D. Jaime no pudo hacer, ni aquellos cien matrimonios lerinenses que metió en Valencia para repoblarla de cristianos, fue cambiar la índole islamita del alma valenciana. De aquí arranca la condición tranquila, indiferente y estoica que los lemosines tienen ante el peligro, condición fatalista, cierta resignación al destino, trasmitida a ellos, lo mismo que a los murciando y andaluces, por el «quietismo» mahometano (p. 502).

Dentro de este bloque podemos citar varios ejemplos, como el caso del Anuario y guía de Murcia (1920), donde en la sección denominada «Definiciones a vuela pluma», bajo el título de «Murcia», y dentro de la sección 'Su fundación' ( $p .5)$, podemos leer:

El rey don Jaime I de Aragón llamado el Conquistador, se apoderó de la ciudad de Murcia, su capital, sacándola del poder de los moros. Entrada en su poder de España, se dice que hubo competencia con Castilla, pretendiendo esta que le pertenecía Habiendo caído de nuevo en poder de los Sarracenos, se apoderó de ella Fernando III el Santo en 1241 por convenio con el Rey de Udiel para ir contra el de Granada. Después el primero de Febrero de 1265 volvió a tomarla el rey don Jaime; y al siguiente pasó al poder de don Alfonso el Sabio, su yerno, por convenio particular.

En el Almanaque benéfico del Asilo de San José de Calasanz. (1924), publicado en la ciudad de Lorca, también es posible encontrar una mención al rey aragonés. En este caso de clara connotación religiosa, ya que se le menciona como referencia para enmarcar históricamente el artículo dedicado a la Cruz de Caravaca. Se trata de una referencia y uso religioso que, posteriormente y con diversos matices, se repetirá en diversos lugares: 
Ramón Doménech Villa. Literatura y sociedad. Algunos ejemplos de la presencia de Jaime I en la Región de Murcia, a través de diversos contextos escritos.

El régulo musulmán Abuzeid, ante el que se cree apareció la Cruz, no fué otro que Abusaid, hijo de Mohamed, hijo de Abuhafs, hijo de Abdelmamem [...], que en 1225 y con ocasión del sitio puesto por los cristianos a Peñíscola, pactó treguas y paces con D. Jaime I de Aragón, declarándose tributario suyo y obligándole a pagarle, en ese concepto, el $5^{\circ}$ de las rentas de Valencia y Murcia (p. 74)

Unos años antes, el 3 de mayo de 1868, el diario El faro murciano-diario de intereses materiales, artes, ciencias y literatura-, aprovecharía el mismo argumento para incluir la figura del rey, dentro de un artículo con la misma temática. En este caso la mención al monarca se observa al referirse al gobernante de la ciudad de Denia: « (...) y por ello arrojarle del trono, poniendo en su lugar á Zeyan Walí de Denia, el cuál a su vez fue destronado por D. Jaime de Aragón, que restituyó al cristianismo el Reino de Valencia, á instancia y con la cooperación de Ceit».

El Boletin Bianual de la Junta del Patronato del Museo Provincial de Bellas Artes de Murcia, (1929: 40-53), recoge un curioso artículo del arquitecto D. José Navarro David, que nos sirve de fuente para la localización de un hecho significativo, relativo la capital de la Región y a su particular historia.

En su recorrido por la ciudad, durante el siglo XIX dentro de su estudio realizado, señala que: «En 1803 se demolió por acuerdo del Ayuntamiento, el arco de «las Siete Puertas», por donde entró en la ciudad musulmana el invicto D. Jaime $\mathrm{I}^{\mathrm{o}}$ de Aragón, en la memorable -iy cuan olvidada! ${ }^{11}$ - fecha del 13 de febrero de $1266 »$.

La referencia a «las Siete Puertas» (lugar ya referido en la justificación inicial) y su simbolismo aplicado a la figura del rey aragonés, es posible leerla en diferentes fuentes. Entre otras la que aparece el 3 de marzo de 1928 en relación a un artículo escrito dentro de la publicación Flores y Naranjos (p.4-5),, publicada en la capital murciana, bajo el título «De la Murcia de antaño - El león del Malecón», como reflejo de largos paseos por la ciudad, a través del emblemático muro:

Cuenta el cronista Ramón Montaner que al ser rendida Murcia musulmana a la corona de Castilla, por el invicto Jaime el Conquistador (1266) hizo su entrada por la principal de las puertas de la ciudad, la que denominaron los historiógrafos «las Siete Puertas», junto a Santa Olaya (Santa Eulalia en la actualidad).

\section{Premios, homenajes, humor y misceláneas.}

En otras ocasiones podemos comprobar la aparición del monarca, en contextos menos rígidos, adaptado a las necesidades del momento y en situaciones de lo más variado.

En esta línea Las Provincias de Levante, número del 25 de abril de 1891, firmado por Eusebio Blasco, y contextualizado en un imaginario examen a un muchacho «colorado y sordo», llegado a Zaragoza

11 Curiosa esta reflexión, de hace casi un siglo, que confirma una de las teorías que desde aquí se defienden, a la vista de la documentación existente, tanto respecto a Jaime I como a sus acciones dentro de la región y de la ciudad de Murcia, así como el reconocimiento y conocimiento de las mismas.

SCRIPTA, Revista internacional de literatura i cultura medieval i moderna, núm. 4 / desembre 2014 / pp. 125 - 146 ISSN: 2340-4841 $\cdot$ doi:10.7203/SCRIPTA.4.4360 
Ramón Doménech Villa. Literatura y sociedad. Algunos ejemplos de la presencia de Jaime I en la Región de Murcia, a través de diversos contextos escritos.

desde Cuarte y acompañado de sus padres: «Como salgas mal, te mato á pellizcos», le dijo su padre. «Como le des un disgusto a tu padre te mato a tozoladas» le señalaba su madre. Con un examinador controlado pues había recibido: «una carta de reconocimiento muy fuerte del coronel de la guardia civil, que está de huésped en casa de los padres del chico y es además primo carnal del profesor supradicho». El lector esbozará una sonrisa con la lectura de las líneas siguientes:

(...) ¿En qué año murió Don Jaime I? (Preguntaba el profesor)

¿Jaime I dice usté?

Sí; Jaime I.

(Silencio y balanceo).

¿Jaime I dice usté?

Sí.

¿Qué en qué año murió?

Sí.

¡El mesmo que lo enterraron!

Muy bien. No hay que apurarse. ¿Qué sabe usted de los Felipes de la casa de Austria?

¿De los Felipes?

Sí; vamos, recuerde usted, saldrá.

Pues mi tío Felipe, el fosero, está en el camposanto de Riela. Mi primo Felipe, el cestero, está

con unas tercianas que se arde...

Vaya usted a cavar, ¡so sinvergüenza!

También encontramos al rey en los espacios dedicados a pasatiempos y similares, tan habituales en determinados momentos. Los autores de la charada del número 11 de la revista del Ateneo de Lorca (p. 8) observaron una buena oportunidad el 10 de abril de 1896, al incluir las siguientes líneas con la forma de acertijo correspondiente:
El primera-cuarta, toda
le suelta un primera-dos
al hombre entendido
tenga dos-tercera o no.
Y dice con desenfado
Y con cierta agitación:
«No tercia-segunda a nadie,
aunque tenga más valor
que tuvo Guzmán el Bueno
o Jaime el Conquistador».

El primero de mayo de 1876, dentro de las páginas de El Eco de Cartagena, en su apartado dedicado a las misceláneas, era posible conocer el porqué de una frase popular como «eso parece el Martes de Játiva», con un paralelismo curioso con el actual «martes y trece», que enseguida se identificará.

Según se nos relata, en referencia al rey de Aragón, a pesar de su tradición victoriosa, fue la batalla en la ciudad valenciana:

Para los de don Jaime tan desastrosa, que se habló de ella durante muchos años. Perdiose la sangrienta batalla en un martes; y desde entonces, cuando ocurría cualquier desastre decían los cristianos: ¡Eso parece el Martes de Játiva! Cuando cualquiera iba a emprender un negocio o a correr cualquier peligro: Cuidad, que es Martes... no te ocurra lo de Játiva. 
Ramón Doménech Villa. Literatura y sociedad. Algunos ejemplos de la presencia de Jaime I en la Región de Murcia, a través de diversos contextos escritos.

Con un toque de mayor seriedad, hablamos de la «Velada a la memoria de Fernández Caballero ${ }^{12}$ », también fue posible comprobar la presencia del rey, dentro de este acto que se le brindaba al músico de origen murciano (citado tambióen en la introducción) y que se celebró en el Teatro-Circo de Murcia.

Entre ellos destaca el que, a raíz del artículo donde se daba cuenta del acto de homenaje celebrado, fue publicado por el diario Región de Levante. Diario Liberal, unos día después de producido el fallecimiento, en concreto el 15 de abril.

El artículo reproduce un extenso romance, la mayoría quintillas de variadas rimas, y en él se realiza un amplio recorrido por la labor de Fernández Caballero. En la composición de Tirso Camacho, con referencia expresa, y con un advertido doble sentido, con el ya comentado juguete cómico-líricobailable en un acto, junto a otras consideraciones del contexto que se pudieran extraer, podemos leer:

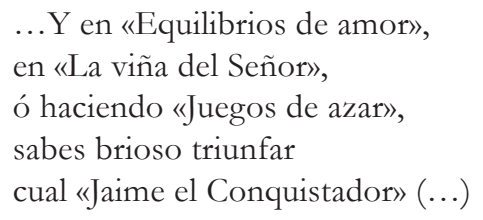

La existencia de convocatorias de premios literarios, a veces procedentes de fuera de la Región, con el trasfondo del monarca y su contexto histórico como argumento conector, también es recogido por los diarios locales, lo que da una idea de la variedad de espacios donde era posible comprobar la presencia, directa o indirecta, de la figura del rey. Dos son los casos referenciados a modo de ejemplo, ambos aparecidos en El Eco de Cartagena.

El primero se produce en la edición del 30 de junio de 1876 y hace referencia a la convocatoria por parte del Ayuntamiento de Valencia de un «certamen histórico-literario en honor del Rey D. Jaime I de Aragón», con motivo del sesto centenario de la muerte del rey. Su objetivo: llegar a los poetas y escritores.

Treintaiséis años más tarde, un 8 de julio de 1912, se recogía el siguiente titular: «Premios de la Academia de la Historia». Los párrafos siguientes desvelarían la presencia como referencia de nuestro protagonista y en qué sentido esta era producida. El anuncio correspondiente del premio en cuestión rezaba así:

La Academia de la Historia anuncia el concurso para otorgar el 1913 el permio de 1.000 pesetas, del marqués de Aledo ${ }^{13}$, al autor de una Historia civil, política, administrativa, judicial

12 Fallecido el 26 de febrero de 1906.

13 Sobre estos premios en estos enlaces podemos consultar otras convocatorias correspondientes a las siguientes fechas:

1916: http://www.euskomedia.org/PDFAnlt/cmn/1915059061.pdf 
Ramón Doménech Villa. Literatura y sociedad. Algunos ejemplos de la presencia de Jaime I en la Región de Murcia, a través de diversos contextos escritos.

y militar, de la ciudad de Murcia y de sus alrededores (la vega o poco más, a reserva de un caso excepcional), desde la reconquista de don Jaime I de Aragón, a la mayoría de edad de don Alfonso XII. (El Eco de Cartagena)

Como dato curioso podemos señalar los matices con los cuales había que tratar el trabajo a entregar. Desde esta perspectiva podemos comprobar lo sutil de la censura correspondiente:

Hasta la muerte de Fernando VII, el historiador podrá juzgar según tenga por conveniente los acontecimientos relatados por él; pero desde dicha época hasta el final de su obra se limitará a reseñarlos, y procurará no dejar traslucir su criterio; procedimiento que se extremará más, según sean más recientes los hechos.

Aunque no se trata de ningún premio como los señalados, es interesante la referencia que apareció el 21 de abril de 1887 en el número III de Lorca Literaria. En un artículo escrito por D. Juan P: Beltrán, dedicado y titulado Juegos Florales (p. 33-35), se podía leer lo siguiente, después de unas líneas anteriores que nos remitían hasta «los primitivos griegos».

En España vemos los primeros certámenes literarios en Valencia, Barcelona y Mallorca en la época del Rey Don Jaime I, el Conquistador, en que inmensa pléyade de poetas provenzales, expresaron en lemosino, sus conceptos y cantaron sus amores en las cortes de Aragón.

\section{Publicaciones religiosas y otras curiosidades patrióticas}

A la redacción de este apartado ya se ha hecho mención con anterioridad. La diversidad de escenarios, así como la justificación para la aparición del rey, son múltiples y variadas, casi adaptables a cualquier perspectiva, solo es cuestión de «girar» la interpretación hasta conseguir el enfoque deseado.

Aunque se parte de una historia muy conocida, en la publicación dominical y murciana La Juventud Literaria, en su número 180 del 24 de septiembre de 1893, bajo el título del artículo «Palique», lo reseñaba bien claro Ramón Blanco, con motivo de la celebración de la fiesta de Nuestra Señora de las Mercedes: «La virgen de las Mercedes, revelada a D. Jaime de Aragón y aparecida al venerable San Pedro Nolasco, fue la enseña gloriosa del siglo XIII del rey conquistador, fundador de la Real y militar orden de redentores cautivos».

Las hojitas del hogar, que se publicaban los sábados «con la censura y aprobación de la autoridad eclesiástica», en su número 293 del año VI de su tirada, el martes 22 de septiembre de 1906 y tras el correspondiente y tradicional «Santoral y Vela», concretamente en la segunda página, dentro de la denominada «Sección Piadosa» y bajo el artículo Los nuevos mercedarios, se refleja una nota a modo de efemérides, correspondiente al año 1218. En concreto decía lo siguiente:

En la noche del $1^{\circ}$ de Agosto del mismo año, aparecióse la celestial Madre de misericordia a San Pedro Nolasco, a San Raimundo de Peñaflor y al rey D. Jaime I, mandándoles fundar una

1917 y 1919: http://hedatuz.euskomedia.org/9631/1/1916005007.pdf

1918-1920: http://hedatuz.euskomedia.org/9704/1/1917163166.pdf

SCRIPTA, Revista internacional de literatura i cultura medieval i moderna, núm. 4 / desembre 2014 / pp. 125 - 146 ISSN: 2340-4841 · doi:10.7203/SCRIPTA.4.4360 
Ramón Doménech Villa. Literatura y sociedad. Algunos ejemplos de la presencia de Jaime I en la Región de Murcia, a través de diversos contextos escritos.

congregación, con el título de las Mercedes, cuyo fin principal fuera la redención de cautivos, llevándose á cabo bajo su protección esta colosal empresa.

El ya mencionado almanaque editado por la Asociación de San José de Calasanz, de la ciudad de Lorca (protectora de niños abandonados) también tuvo un recuerdo y mención para Jaime I. Fue en este caso el que se publicó para el año 1915. En su recorrido por las iglesias de la ciudad le tocaba el turno a la de Santa María, Cruz y Custodia. Esta es la descripción de la misma que nos ofrece la publicación (p. 84): «Según la tradición esta iglesia es una de las dos mil que, bajo la advocación de la Virgen María, fundó el rey D. Jaime I de Aragón; pero su actual estilo es del siglo XV (...)».

En una línea similar, la publicación quincenal Alma Joven, con sede en la ciudad de Murcia, publicaba, allá por el 1 de junio de 1918, el artículo titulado Desde el vergel de Valencia. La Inmaculada y los reyes de España. En el recorrido por Ervigio, Sisebuto, Sienando y Chindasvinto, junto a Wamba, García IV, Fernando III y Alfonso X, Juan I de Aragón, Martín el Humano, Juan II de Navarra y Juan II de Aragón, con los Reyes Católicos incluidos, se echaba en falta a un: «Jaime I el Conquistador que extendió la fiesta del 8 de Diciembre».

Desde El Eco de Cartagena, con motivo del Gran Centenario de San Vicente Ferrer, también se realizaba mención al rey, después de un emotivo artículo con citas y descripciones de todo tipo, acerca del sentimiento del pueblo valenciano ante la celebración. Al inicio de un nuevo párrafo encontramos un recorrido histórico-literario de España, donde se puede leer:

Después de la centuria decimotercera, la mejor de la Edad Media, en que reinaron en Castilla monarcas cumbres como San Fernando y Alfonso el Sabio, y en Aragón otros no menos excelsos como don Jaime el Conquistador y Pedro III el Grande; centuria de portentoso desarrollo cultural en que Ciencias, Letras y Artes se desenvuelven prodigiosamente, así como las instituciones políticas... (22-04-1919)

Amory Esperanza era un periódico parroquial y quincenal, que se publicaba en la ciudad de Alhama de Murcia. En su número 143 del lunes 6 de enero de 1930, los alhameños pudieron leer un artículo sobre la fundación de su ciudad para la que «hay que remontarse a los primeros siglos de la Era Cristiana». En esta publicación, de marcado carácter religioso, también se podían leer reseñas relativas a la historia del municipio:

Posteriormente la conquistaron los moros y sobre las obras defensivas de los romanos hicieron sólidas fortificaciones como se advierte en el recinto amurallado y torre del castillo, hasta que reconquistada por Jaime I la cedió a Castilla y ésta a los Marqueses de Villafranca.

Dos referencias, para terminar este apartado, que han llamado la atención, por fechas y por el lugar de difusión. Ambas se encuentran en la publicación Liceo Azul, editada por la Organización Juvenil Española (OJE), de la ciudad de Lorca.

En la primera de las citas, publicada en el mes de marzo de 1962, existía un artículo dedicado a la reconquista de la ciudad: Historia de Lorca, en él, el alumnado del tercer curso de Bachillerato del Instituto José Ibáñez Martín, exponía su trabajo, narrando la situación del la siguiente manera: 
Ramón Doménech Villa. Literatura y sociedad. Algunos ejemplos de la presencia de Jaime I en la Región de Murcia, a través de diversos contextos escritos.

La dominación árabe en España comenzaba ya una curva descendente cuando alboreaba el siglo XIII.

El rey moro de Murcia, impresionado por la brillante campaña de don Jaime I, conquistador de Baleares y Valencia, rindió vasallaje al monarca de Castilla, don Fernando. Sin embargo, tres plazas murcianas se opusieron a esta sumisión: Lorca, Cartagena y Mula.

La misma publicación, tres meses más tarde, se hace eco del campamento que los jóvenes de la localidad habían celebrado durante el verano anterior. Esta actividad se recoge en el ejemplar de agosto y septiembre. La experiencia, que había tenido lugar en la isla de Mallorca, se describe a lo largo del artículo, indicando solemenemente en uno de los párrafos que:

Por último, Santa Ponsa, rincón de singular interés por la belleza del paraje y su gran importancia histórica. Allí, según es sabido, desembarcó para la conquista de Mallorca Jaime I de Aragón. Ante la cruz que conmemora el acontecimiento, la lección correspondiente al día y al lugar.

\section{Jaime I como referencia para el estudio de la historia de la Región de Murcia, los murcianos y de sus vecinos geográficos. Una perspectiva didáctica.}

Realidad o leyenda, en sus apariciones, el rey de Aragón queda justificado como hilo conductor y protagonista en un amplio abanico de ámbitos. Su aparición y referencia, se podía producir en el momento y lugar menos pensado por el lector.

El primer ejemplo de este apartado se incorpora porque, además de interesarnos dentro del marco del presente trabajo, formaría parte de ese aprendizaje llamado hoy en día informal, capaz de demostrar la potencialidad y posibilidades de conocimiento, fuera de los marcos tradicionales, a cualquier edad y desde cualquier medio, siempre que esté bien planteado y justificado. Una constante que se podrá repetir en la gran mayoría de referencias que vamos a observar respecto a la figura del monarca en este apartado.

El artículo inicial aparecía en un periódico de la ciudad de Yecla, comarca del Altiplano murciano. Fechada en abril de 1988, despertó la curiosidad porque, al mismo tiempo que hablaba en su portada de convenios o de ferias de muestras, era posible encontrar en su interior un artículo firmado por Aniceto López Serrano, en la sección Historia, bajo el título: «Una institución olvidada: El Marquesado de Villena (Orígenes y formación)». En él, además del amplio recorrido que realizaba, de gran interés sin duda, en su segundo párrafo se podía leer este dato histórico al que que despertó el interés:

Al finalizar el primer tercio del siglo XIII los esfuerzos conquistadores de Fernando III de Castilla y Jaime I de Aragón, van a confluir justamente en los territorios que después formarán el Marquesado de Villena. El príncipe D. Alfonso, el Sabio, recibe en 1.244 el vasallaje de Ben Hud, rey Moro de Murcia. En 1240 Jaime I había conquistado Villena y en 1243, D. Alfonso había ocupado Yecla y algunas villas más del norte del reino de Murcia. 
Ramón Doménech Villa. Literatura y sociedad. Algunos ejemplos de la presencia de Jaime I en la Región de Murcia, a través de diversos contextos escritos.

Más de cien años antes, en El Eco de Cartagena, un día antes de la Nochebuena de 1875, publicaba en su primera página el artículo «Apuntes históricos y artísticos sobre la antigua catedral de Cartagena», para finalizar se señalaba que: «Hasta aquí las primeras noticias históricas de la antigua catedral ${ }^{14} \mathrm{de}$ Cartagena, de cuya población no se vuelve a hablar hasta la reconquista de Murcia por Don Jaime I». Para continuar dos días después la columna diciendo:

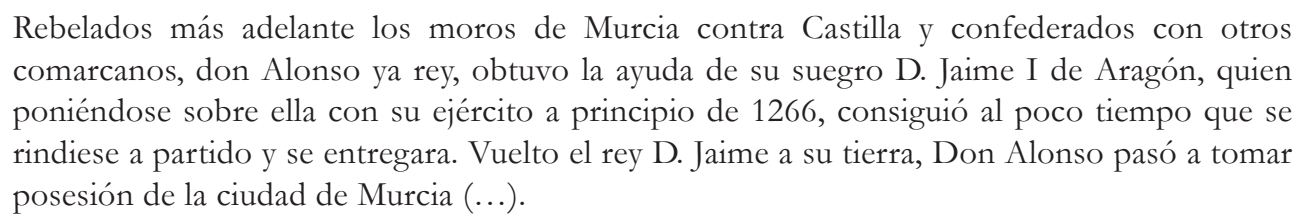

La cuestión relativa a las fechas y la llegada de D. Jaime a Murcia parece que no estaban muy claras. Prueba de ello es la siguiente descripción, según el mismo diario, unos cuantos años más tarde. Podemos apreciar algún ligero cambio en la línea editorial, pues desde un titular muy reivindicativo «Cartagena, lo que ha sido y lo que tiene derecho a ser», se podía leer en su interior:

Después de veinte años, el rey moro de Murcia trató de sacudir su vasallaje, y el ya rey D. Alfonso que se hallaba ocupado en la frontera de Jaén, rogó a su suegro el de Aragón, D. Jaime el Conquistador, que entrase en el territorio murciano y sometiera á sus rebeldes vasallos. Hízolo así D. Jaime, y después de su riguroso cerco por tierra y mar, espagnó a Cartagena poblándola con caballero y hombres de armas de sus huestes, valencianos, catalanes y aragoneses. (El Eco de Cartagena, 11-05-1877)

El lector de finales de siglo XIX se podía convertir en un auténtico experto en lo relativo a la figura del rey D. Jaime, poseyendo un poso literario e histórico muy digno y relacionado con diferentes ámbitos temáticos. Prueba de ello son las tres noticias que a continuación se señalan. Bajo una temática genérica común es posible la lectura de unos artículos muy interesantes, que incluyen una perspectiva comparatista adecuada a las necesidades. Tres fuentes distintas: La Enciclopedia ${ }^{15}$, La Jwventud Literaria y Cartagena Artística, publicadas en tres años (1888, 1889 y 1890), bajo líneas periodísticas distintas, extensible también al lugar de edición.

Un primer artículo con el título «Resumen comparativo de las civilizaciones romana y árabe en España VII», escrito por Don Andrés Blanco y García. En él aparecen referencias de todo tipo desde el enfoque político, administrativo o artístico. Prueba de ello son las siguientes líneas, en relación al arte decorativo musulmán:

14 Parece que las dos ciudades también compartieron cuestiones relativas a la existencia y presencia de su catedral. Curiosamente el rey de Aragón también aparece como referencia en otro artículo de parecidas características. «Apuntes sobre la catedral de Murcia», aparecido el 31 de mayo de 1897 en Las Provincias de Levante, que señalaba lo siguiente sobre el edificio, dentro de la subsección Traslación a Murcia: «Conquistada Murcia para la corona de Castilla por D. Jaime I de Aragón el 13 de febrero de 1265, fue consagrada la mezquita mayor de los árabes por el santo fundador de la orden de la Merced San Pedro Nolasco, bajo la advocación de la Santísima Virgen María, como iglesia principal de la ciudad de Murcia».

15 «Revista semanal de conocimientos útiles, ciencias, artes, literatura, modas, profesiones, pasatiempos y guía de Murcia». 
Ramón Doménech Villa. Literatura y sociedad. Algunos ejemplos de la presencia de Jaime I en la Región de Murcia, a través de diversos contextos escritos.

Estos mosaicos de ladrillo esmaltado que al principio se componían de piezas muy pequeñas de 2 por 3 pulgadas, fueron tornando proporciones con el tiempo hasta convertirse en la loseta esmaltada que en tiempo de la conquista de Valencia por D. Jaime I -1236- era labrada por los moros con el nombre de rájolas y hoy se conoce con el de azulejos. La voz rájola es árabe adoptado en el dialecto valenciano y significa azulejo. (La Enciclopedia, 11-12-1888)

También de excepcional puede calificarse el artículo, por extensión y contenido, que presentó el 17 de marzo de 1889 la publicación La Juventud Literaria ${ }^{16}$. El estudio comparativo de las reformas legislativas de Alfonso X de Castilla y Jaime I el Conquistador queda reflejado. A raíz de la introducción se establece una línea entre los códigos legislativos de ambos reyes; la situación previa y la redacción, con referencias constantes a los fueros iniciales y a sus diferentes títulos. Todo un ejercicio de conocimiento para el lector de la época. Las referencias a los dos monarcas son constantes y extensas. Sin embargo señalaría, a modo de ejemplo, como el autor, Modesto Hidalgo, cierra las tres extensas columnas del estudio, pues en él también se respira el tono con el que habían sido tratadas las dos figuras, a lo largo del artículo:

En resumen y para terminar, diremos que si Jaime brilló como guerrero, no obtuvo iguales éxitos como legislador, no así Alfonso X que legó á la nación una noción tan perfecta que aún á pesar de lo mucho que se ha progresado, ha sufrido ligerísimas reformas. (La Juventud Literaria, 17-03-1889)

Terminamos con una tercera referencia desde una perspectiva literaria. Un artículo publicado en Cartagena Artística el 10 de junio de 1890. Firmado desde Valencia por Teodoro Balaciart Tormo, su importancia reside en varios frentes: por un lado en el hecho de comprobar la prensa como instrumento para la difusión y enriquecimiento cultural; por otro corroborar cómo, hace más de un siglo, era posible encontrar colaboraciones que procedían más allá de límites geográficos, algo que nos debe hacer reflexionar sobre la admiración o lazos de cooperación entre diferentes realidades, sin otro tipo de interés, más que el cultural, y una última cuestión referida a la confirmación sobre el grado de estudio y conocimiento detallado de los temas desarrollados.

Si en la referencia anterior citábamos el final del artículo, y su comparativa con Alfonso y Jaime, ahora las miradas están puestas en el inicio de Una conquista sin sangre, por aquello que decíamos de las perspectivas, dentro del análisis de la misma figura:

Don Alfonso X, rey de Castilla, que como sabe todo el mundo, fue un monarca poderoso, respetado y llamado el Sabio por la posteridad, probó plenamente los azarosos días de su turbulento reinado, que la inteligencia más privilegiada no basta á alcanzar una mínima parte del saber humano.

Legislador aventajado a su siglo en las partidas; poeta sentido y culto en sus Cántigas; matemático profundo en sus Tablas Alfonsinas, fue un mal político y un pésimo administrador de sus reinos (...).

El hijo de San Fernando y de Beatriz de Suavia, olvidándose de la herencia paterna, malgastó tiempo y dinero en disputar la corona imperial de Alemania, desprendida de la cabeza de los Hoenstauffen mientras su suegro, el hábil Jaime I de Aragón casaba á su hijo el infante

16 Que se publicaba jueves y domingos. 
Ramón Doménech Villa. Literatura y sociedad. Algunos ejemplos de la presencia de Jaime I en la Región de Murcia, a través de diversos contextos escritos.

D. Pedro con la nieta de Federico II, y preparaba de este modo el engarce en la diadema aragonesa del hermoso reino de Manfredo de Sicilia. (Cartagena Artística, 10-07-1890).

Serían innumerables las coincidencias en esta línea aparecidas en los más diversos contextos, sin embargo, la última mención de este bloque, se hace por rozar los límites de lo anecdótico.

Varios son los motivos que llevan a ello. Se trata de una publicación realizada en un cuartel militar, el de «Carraclaca» de Lorca, nombre del que la revista toma su título: Carraclaca - Semanario para el soldado, donde tenía su sede el Regimiento de Infantería Mallorca $n^{\circ} 13$. En segundo lugar por la fecha: Año II; $\mathrm{n}^{\circ}$ 21; 20-3-1945, por último por el contexto; donde aparece el monarca aragonés, y acompañado de quién. Así, en el artículo «Formación de la Patria Española», en sus primeras líneas, era posible leer lo siguiente, escrito por José A. Vicente (P. M: Mando):

Leemos en la Historia de España, que concluida la Reconquista aragonesa con las brillantes campañas de Jaime el Conquistador y casi dado fin a la Reconquista Castellana con las batallas de los Fernandos y Alfonsos, cayeron ambos poderosos reinos en un estado de anarquía horrible.

Por supuesto que el artículo terminaba citando y relacionando la rey Jaime con nombres de infausto recuerdo, totalmente fuera de contexto, incluyendo referencias que todos podemos imaginar y que no merece la pena traerlas a este lugar.

\section{Un rey, de literatura para la Región de Murcia y la investigación histórica.}

Profundicemos en el carácter más literario y, por extensión, llevémoslo a otro tipo de publicaciones e investigaciones, que presenten una relación distinta con la Región, a lo referido hasta el momento. Sería imposible citar todas las publicaciones donde se constate la aparición de nuestro protagonista, sobre todo las relativas a enfoques históricos y sus ramificaciones. Lo que si nos podemos hacer una idea es sobre cuáles son los tipos de contextos donde su figura hace acto de presencia, con estos enfoques más ligados a literatura e investigación.

Antes de seguir es importante recordar que la Región de Murcia, como comunidad uniprovincial, es de muy reciente creación (1978). Sería sencillo encontrar referencias a Jaime I en escritores e historiadores nacidos en la provincia de Albacete, con la que formaba la denominada Región Murciana (y con anterioridad el Reino de Murcia), estas apariciones no han sido incluidas en la presente publicación.

Para nuestra primera parada centraremos la atención en la obra del murciano Félix Ponzoa Cebrián: Historia de la dominación de los árabes en Murcia, sacada de los mejores autores, y de una multitud de códices y documentos auténticos de aquella época, que existen en las bibliotecas y archivos del reino. Publicación que vio la luz en Palma de Mallorca en 1845, y que era, en boca de su autor en su dedicatoria inicial a D. Joaquín María Bover de Rosselló: «un pequeño trabajo histórico».

En esta obra encontramos manifiesta la aparición del rey D. Jaime en los capítulos ordenados de 
Ramón Doménech Villa. Literatura y sociedad. Algunos ejemplos de la presencia de Jaime I en la Región de Murcia, a través de diversos contextos escritos.

manera cronológica, relativos a su presencia en Murcia. Tal es el caso del XXIII y siguientes ( $\not$. 125-200), destacando en esta línea el segundo apéndice destinado a los «Capítulos de la Crónica de D. Jaime I, que tratan de la conquista de Murcia», presentada en dos columnas con el texto original y la correspondiente traducción, a la que precede este comentario:

\begin{abstract}
Esta crónica es el rayo de luz, que separa en nuestro asunto la fábula de la historia: los murcianos, los españoles todos tienen un interés en saberla. Por lo que respecta a la conquista de Murcia, es también deber mío el publicarla; y yo espero el día (que no se debe tardar) de que toda adorne y eleve á nuestras bibliotecas y honre á la literatura española. (íb. 216)
\end{abstract}

Mucho más curiosa es la siguiente publicación, que serviría para engrosar el apartado dedicado a aquellos aspectos de perspectiva más literaria, en la referente a su presencia en obras donde se relatase su paso por tierras de la Región. El ejemplo en cuestión lo encontramos pocos años después de la referida publicación anterior, el 9 de febrero de 1848, cuando se representaba en el Teatro Variedades La conquista de Murcia por D. Jaime de Aragón, drama histórico en tres actos, dividido en cuatro cuadros, y en verso, por D. Juan de Alba y D. Cipriano López Salgado, localización que tiene lugar desde la noche del 2 de enero hasta la del 2 de febrero de $1265^{17}$.

Dos obras servirían para ejemplificar el perfil literario (y musical), de esta sección, centrada durante el siglo XIX. La primera, y ya referenciada, aquella que contó con la participación del murciano Manuel Fernández Caballero, con la aportación de su genio musical, en el juguete cómico-líricobailable, en un acto, D. Jaime el conquistador.

La segunda es el Romancero de don Jaime el Conquistador, original del cartagenero Adolfo Llanos y Alcaraz, premiado con la Medalla de Oro de la Real Academia Española ${ }^{18}$. Autor al que Cartagena Artística (Ciencias, Artes y Literatura), en su número del 10 de marzo de 1892, dedicó en un extenso artículo, portada y páginas interiores, escritas por Mariano del Todo Herrero.

Romancero donde podemos leer, entre otras composiciones, esta Conquista de Murcia, dentro de la sección «Triunfos Providenciales» (íb. 119-120):
A Murcia llega Don Jaime:
La ciudad quiere rendir,
Mostrando arrebatadora
Impaciencia juvenil. [...]
Los valerosos murcianos
Doblan la altiva cerviz;
Al sabio Rey de Castilla
Don Jaime dice así:

\footnotetext{
17 Comprobamos aquí también las diferentes interpretaciones de fechas, a las que ya se han hecho alusión, dependiendo de la fuente correspondiente.

$18 \mathrm{Y}$ dos mil pesetas.
}

SCRIPTA, Revista internacional de literatura i cultura medieval i moderna, núm. 4 / desembre 2014 / pp. 125 - 146 
Ramón Doménech Villa. Literatura y sociedad. Algunos ejemplos de la presencia de Jaime I en la Región de Murcia, a través de diversos contextos escritos.

\footnotetext{
$-\ll$ Tronos quedan a mis hijos.

Tronos puedo repartir.

Tuyo es el reino de Murcia,

Lo he ganado para tì.
}

Diferentes tipos de ejemplos encontramos dentro de los autores más representativos de la literatura de reflejo de la huerta murciana.

Uno de los más destacados en estas lides, el costumbrista Pedro Díaz Cassou (Murcia, 1843 Madrid, 1902), es consciente de esta situación pues, preocupado por el ámbito de la huerta y sus problemas de regadío (ya en aquella época) destacó por su interés en la creación de una Cátedra de Agricultura. Curioso es este caso que ahora se reseña pues, si no de manera directa, sí Francisco Silvela, escribió en el prólogo a la obra del murciano: La huerta de Murcia. Ordenanzas y costumbres, unas significativas líneas que impregnarán el resto de la obra del Díaz Cassou y sus intereses, que deberían servir de obligada reflexión:

\footnotetext{
Conquistada Murcia por los monarcas aragonés y castellano, último pueblo de la corona de Castilla y próxima al último pueblo de la corona aragonesa, poblada casi en proporción igual por aragoneses y castellanos y aislada, ó pocos menos, del resto de España por dificultades topográficas, pudo ser Murcia la mejor escuela de arte y derecho del regadío, conservar mejor aquel estado antiguo que tanto y tan poco eficazmente recomendaba D. Jaime el Conquistador a los regantes de Valencia, y sobre el precedente árabe operar con menos exclusivismos y por lo mismo con más probabilidades de acierto la obra de refundición que ha llegado á hacer de aquellas huertas del Segura, modelo de regadíos.
}

Como más significativo podemos señalar el siguiente ejemplo, pues otro destacado escritor y poeta en dialecto murciano, José Frutos Baeza (11 de enero de 1861 - 29 de marzo de 1918)-denominado por el escritor de Alcantarilla Pedro Jara Carrillo, como el último panocho- en su poema El habla de Murcia $^{19}$, escribía lo siguiente en una de sus estrofas:
No es el lenguaje panocho jerigonza de burdel, sino mezcla del sencillo romance de pura ley, y del habla vigorosa de aquel pueblo aragonés que conquistador de Murcia con el rey Jaime fue; matizado con mil nombres que dejó el árabe en él, como Alquiba, Zaraiche, Beniaján, Benialé, Alberca, Aljufia, Alfande, Benetúcer, Aljucer, Almohojar, Alfatego, Benicotó y Beniel;

19 En otras fuentes también denominado El habla buertana 
Ramón Doménech Villa. Literatura y sociedad. Algunos ejemplos de la presencia de Jaime I en la Región de Murcia, a través de diversos contextos escritos.

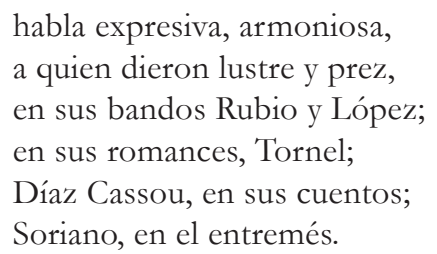

La presencia de D. Jaime, desde la perspectiva de su importancia histórica, ha servido como contextualización para la justificación del murciano como lengua de tránsito y la lógica influencia del rey y los repobladores que con él acudieron, y en tierras murcianas se quedaron. Tal es el caso, por citar un ejemplo de los muchos existentes desde la vertiente de investigación filológica, del artículo presentado por las profesoras Pilar Díaz de Revenga e Isabel García Díaz, de la Universidad de Murcia. ${ }^{20}$

Alejado de este contexto, pero relacionado con el uso del habla propia de la huerta de Murcia, resulta interesante y curioso, descubrir dos publicaciones próximas en el tiempo, ya insertadas en el siglo XX. Ambas comparten multitud de puntos en común, aunque el más importante, para nuestros intereses, es aquello relativo a la figura del rey.

Nos referimos al sainete del polifacético (músico, escritor, folklorista...) Luis Federico Viudes (1943-2008) Los amantes de Beniel (tonta ella, tonto él) o la torre de babel tragicomedia neogótica de ambiente castellano-aragonés, escrita en 1984 y representada en 1985 por el grupo de teatro Alquibla.

Entre sus personajes contamos con: «D. Jaume I de Aragón. - Rey de Aragón; conde de Cataluña; padre de doña Violante y, por tanto, suegro de D. Alfonso X el Sabio».

Donde ya en el prólogo encontramos las siguientes apariciones, bajo el romance (interpretado por una romancera), que lleva por título El que parte et reparte...

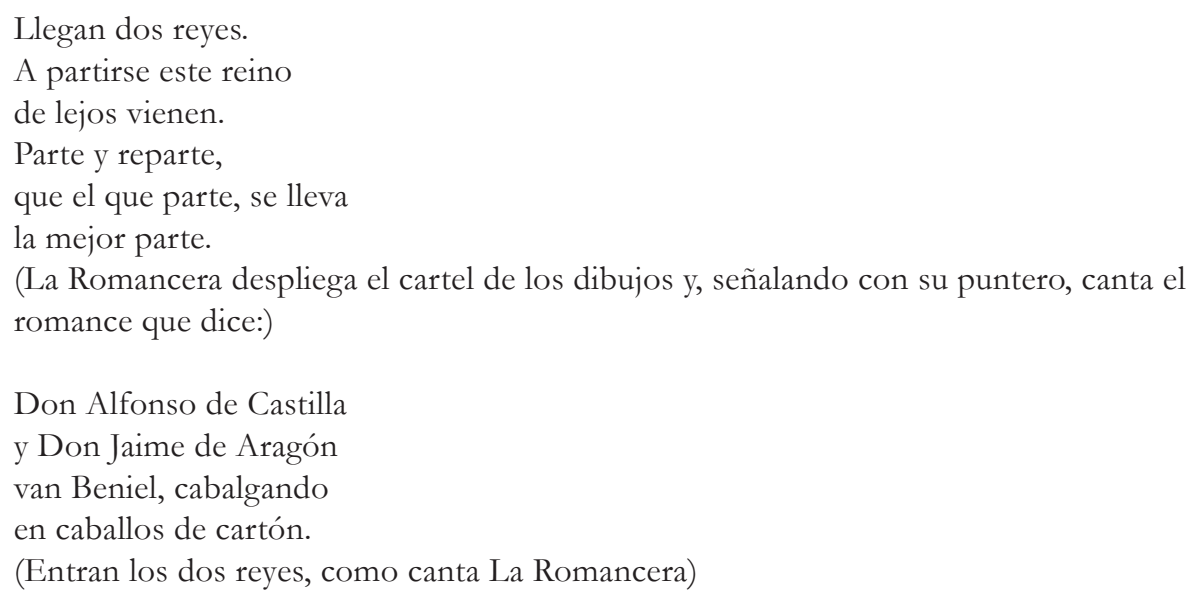

20 Historia y lengua en el Reino de Murcia bajomedieval, publicado en la Revista de Estudios de Lingüistica Universidad de Alicante, en su número 8 del año 1992 (pp. 85-98). 
Ramón Doménech Villa. Literatura y sociedad. Algunos ejemplos de la presencia de Jaime I en la Región de Murcia, a través de diversos contextos escritos.

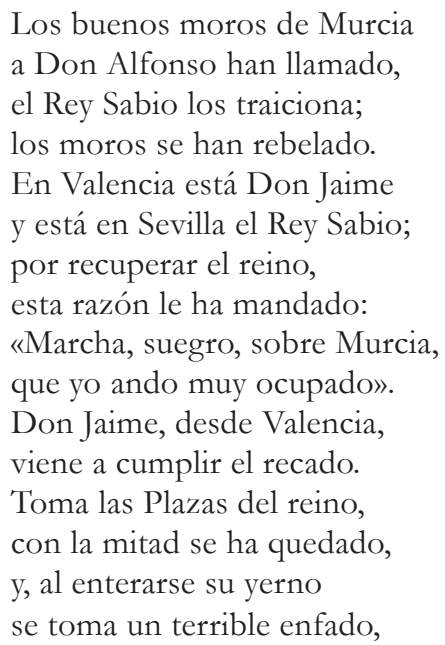

Cinco años después, saldría de la imprenta una obra escrita por Diego Ruiz Marín, Baldomero Ferrer García «Baldo» y José Ma López Martínez, su título: Liciones d’historia d’España (1990). Los tres autores, imitando de nuevo el lenguaje de la huerta de Murcia, ofrecían un panorama muy particular de la historia de España y de la Región, sin perder de vista el humor y la particular visión del huertano.

En tres capítulos es posible encontrar la figura del Conquistador: el central sobre la figura del Don Jaime: El rey Jaime en Cobatillas (capítulo XIV), el XIII: Cristianos y moros se enreann ${ }^{21}$ y el XV: Los moros se apestillan en Graná.

Las palabras que el autor del prólogo (López Martínez) dedica en él al capítulo XIV señalado, se convierten en una interesante reflexión que guarda mucho sobre sus intenciones:

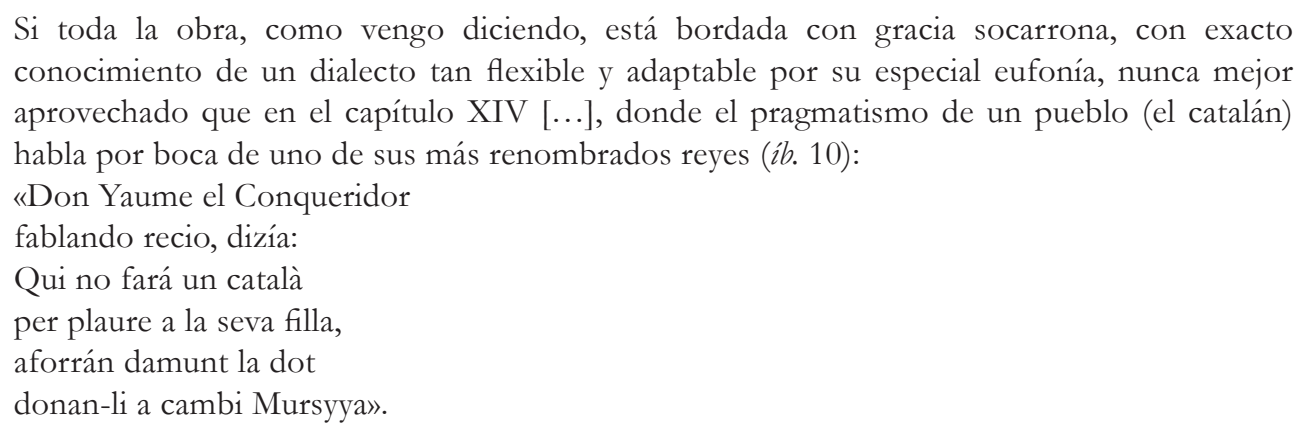

Desde otra perspectiva, la de la investigación y la historia, encontramos otro curioso material del murciano Pancracio Celdrán Gomariz (Murcia 1942), quien en 1980, y en formato de audiolibro, publica en colaboración con el Ministerio de Cultura: Jaime I, el conquistador: plenitud del reino catalanoaragonés $^{22}$.

21 En el interior del libro, una vez en el desarrollo de los capítulos correspondientes, el título que aparece es Cristianos y moros la enrean.

22 Celdrán, P. (1980) Jaime I, el Conquistador: plenitud del reino catalano-aragonés. Madrid. Ministerio de Cultura. Secretaría Técnica (audiolibro). 
Ramón Doménech Villa. Literatura y sociedad. Algunos ejemplos de la presencia de Jaime I en la Región de Murcia, a través de diversos contextos escritos.

Desde esa visión de la investigación histórica, la figura del rey Jaime, ha sido bastante tratada en la multitud de publicaciones existentes y editadas en la Región de Murcia, tanto a nivel de los historiadores e investigadores autóctonos, como a raíz de congresos o las múltiples publicaciones editadas por organismos o instituciones. Es obligatoria la cita de un historiador de la talla de Juan Torres Fontes (Murcia 1919-2013), quien a través de sus cerca de mil publicaciones (entre artículos, libros, prólogos, estudios...), trató en muchos de ellos la figura de Jaime I y su presencia en la Región.

El historiador ya había conseguido el premio «Francisco Cascales», otorgado por la Diputación Provincial de Murcia en el año 1965, por su obra La reconquista de Murcia por Jaime I de Aragón ${ }^{23}$, publicada en 1967 y con una segunda edición en 1987, de la Academia Alfonso X el Sabio.

Obra a la que podemos añadir otras publicaciones en la misma línea pero en diferentes contextos como: Jaime I y Alfonso X: dos criterios de repoblación; Alicante y su puerto en la época de Alfonso X el Sabio y Jaime I, Un rey de gran prez: ${ }^{24}$.

La investigación de la figura de Jaime I estuvo siempre ligada a la obra de Torres Fontes, como prueba de ello podíamos ver la aparición del monarca en algunos de los artículos que, en dos volúmenes, se publicaron por parte de la Universidad de Murcia ${ }^{25}$, a raíz del homenaje que se le rindió con motivo de su jubilación.

En esta misma línea, es posible citar otros ejemplos de murcianos o escritores ligados a la Región, con referencias implícitas, tal es el caso de la medievalista María del Carmen Veas Arteseros en libros como Mudéjares murcianos: un modelo de crisis social (ss. XIII-XV ${ }^{26}$ ) o la del catedrático de Historia Medieval de la UMU, Ángel Luis Molina Molina, con publicaciones como La sociedad murciana en el tránsito de la edad media a la moderna, donde, además de sus investigaciones históricas, encontramos referenciada y contextualizada ${ }^{27}$ las obras de Torres Fontes, que antes hemos citado, como fuentes imprescindibles para el conocimiento de la Región, ligado ello a la figura del Conquistador.

\section{Bibliografía}

23 La reconquista de Murcia en 1266 por Jaime I de Aragón, (1967). Diputación Provincial, Murcia. [2a edición. 1987 Academia Alfonso X el Sabio, Murcia].

24 «Jaime I y Alfonso X: dos criterios de repoblación», (1960) en Actas del VII Congreso de Historia de la Corona de Aragón, Barcelona, pp. 324-340. «Alicante y su puerto en la época de Alfonso X el Sabio y Jaime I» (1976) en Revista de Estudios Alicantinos, XIX, Alicante pp. 11-23. "Un rey de gran prez», en Septimo Centenario de la muerte de Jaime I el Conquistador, 1276-1976. (1978) Memoria de los actos conmemorativos, Madrid, pp. 109-112.

25 VV. AA. (1987) Homenaje al Profesor Juan Torres Fontes (2 Vols.) Murcia, Universidad de Murcia y Academia Alfonso $\mathrm{X}$ el Sabio.

26 Veas Arteseros C. (1992)Mudéjares murcianos: un modelo de crisis social (ss. XIII-XV). Excmo. Ayto. de Cartagena. Concejalía de Cultura. Cartagena.

27 Trabajos que también aparecen citados en el artículo de Pilar Díaz de Revenga e Isabel García Díaz, señalado unas líneas más arriba.

SCRIPTA, Revista internacional de literatura i cultura medieval i moderna, núm. 4 / desembre 2014 / pp. 125 - 146 ISSN: $2340-4841 \cdot$ doi:10.7203/SCRIPTA.4.4360 
Ramón Doménech Villa. Literatura y sociedad. Algunos ejemplos de la presencia de Jaime I en la Región de Murcia, a través de diversos contextos escritos.

Alba de, J. \& López C. (1846) La conquista de Murcia por D. Jaime de Aragón, Madrid, Vicente de Lalama.

Almanaque del Asilo de San José de Calasanz (1915), Lorca, Est. Tip. Luis Montiel.

Almanaque del Asilo de San José de Calasanz (1924), Lorca, Casa Montiel.

Anuario guía de Murcia y su provincia (1920), Murcia, L. y M. Medina.

Boletín de las Cámaras oficiales de Comercio, Industria y Navegación y Agricola (31-7-1909), Murcia, Imprenta Sucesores de Nogués.

Boletin de la Junta de Patronato del Museo Provincial de Bellas Artes de Murcia, 1928-1929 (1929), Murcia, Talleres Trinidad.

Flores y Naranjos (1928), Murcia, Imprenta de Carlos García.

Granés M. \& Cotó A. (1898) El Rayo, un juguete cómico-lírico, rápido, eléctrico y fulminante en prosa, verso y dos cuadros, Madrid, R. Velasco.

Díaz Cassou, P. (1889) Ordenanzas y costumbres de la Huerta de Murcia, Madrid, Fortanet.

Fernández Caballero, M. \& Jaques, F. (1889) D. Jaime el Conquistador, Madrid, R. Velasco.

Ferrer, B., Martínez, J. M. \& Ruiz, D. (1990) Liciones d'Historia d'España, Murcia, El Taller.

Lorca Literaria, nº 3. (1887), Lorca, Imprenta El Noticiero.

Llanos y Alcaraz, A. (1889) Romancero de Don Jaime el Conquistador, Madrid, Imprenta M. Tello

Molina, A. L. (1996) La sociedad murciana en el tránsito de la Edad Media a la Moderna, Murcia, Servicio de Publicaciones de la UMU.

Ponzoa Cebrián, F. (1845) Historia de la dominación de los árabes en Murcia, sacada de los mejores autores, y de una multitud de códices y documentos auténticos de aquella época, que existen en las bibliotecas y archivos del reino, Palma de Mallorca, Imprenta Juan Guasp.

Viudes, L. F. (1985) Los amantes de Beniel, tonto ella y tonto él. (Fondo Compañía de Teatro Aquibla). 